\title{
Blended Learning: Beyond Initial Uses To Helping To Solve Real-World Academic Problems
}

Mark A. McCarthy, DePaul University, USA

Elizabeth A. Murphy, DePaul University, USA

\begin{abstract}
Blended learning strategies can be employed in innovative ways to solve real-world academic problems across all academic disciplines. This article can provide administrators and faculty with specific examples to guide them when making decisions about academic planning or institutional strategies for any discipline at all levels of higher education.
\end{abstract}

Keywords: blended learning, institutional strategies, academic planning

\section{INTRODUCTION}

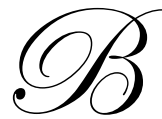

lended courses, often defined as those with between 30 percent and 79 percent of the course content delivered online (Allen, Seaman \& Garrett, 2007), have by now been extensively used within U.S. higher educational institutions. When the movement to create and develop blended courses was in its infancy, the anticipated benefits included:

- $\quad$ By moving a substantial amount of learning online, institutions could reach new student markets by creating weekend and/or evening programs.

- $\quad$ Less class time would result in less time spent commuting for working students.

- $\quad$ Students would be able to complete programs in less time.

- $\quad$ Students would be motivated to be more accountable for their own learning, as blended coursework requires students to be "self-starters".

- $\quad$ Faculty would be invigorated by the opportunity to teach in new ways.

- Institutions would be able to increase enrollments without building more "brick and mortar" classrooms. (Moore 2004; Parry 2009)

- $\quad$ Faculty would spend less time lecturing and more time guiding students and interacting with them.

- $\quad$ Students would spend less time passively listening to lectures, and more time actively engaged in course assignments.

Now that blended courses are no longer in their infancy, a recent study by the Sloan Consortium (Sloan-C) (Allen, Seaman \& Garrett, 2007) sheds a significant amount of light on the uses of and opinions about blended courses. The study's findings include:

- Institutions consider blended courses to be a discrete option, separate from face-to-face courses and fully online courses, and do not consider blended courses merely as part of a transitional strategy from face-toface to fully online courses.

- $\quad$ Frequency of use of blended courses within institutions is very similar to that of fully online courses.

- $\quad$ Blended courses are generally not perceived as holding more promise, in terms of having a higher acceptance and/or a higher perceived value, compared to fully online courses.

- $\quad$ Consumers prefer blended delivery much more than their reported experience with it, and consumers are open to the idea of blended delivery to an even greater degree. 
Graham (2004) notes that designers of blended learning systems should be seeking out best practices for how to combine instructional strategies in face-to-face and computer-mediated environments that take advantage of the strengths of each environment.

\section{USING BLENDED LEARNING TO SOLVE REAL-WORLD ACADEMIC PROBLEMS}

Typically, discussions about the usefulness of blended learning have tended to emphasize the traditional scenario, i.e., the desire to move a substantial amount of learning online, and to limit face-to-face class time, in order to achieve the benefits mentioned earlier. Many institutions have made extensive use of this model. For example, at DePaul University, the Kellstadt Graduate School of Business offers its "Weekend M.B.A" program. Face-to-face meetings are limited to five Saturday afternoons, reducing class room time from thirty to twenty hours. Online videos and assignments are used between the Saturday meetings to deliver the rest of the course content. Student and faculty feedback indicate that a number of the traditional benefits of blended courses have been achieved.

Interestingly, blended learning can be used in ways that perhaps were not anticipated when this tool was first introduced. Just like the Sloan Consortium provides a synthesis of effective practices for online learning (Moore 2008), the following scenarios describe real-world academic problems that can be solved or reduced through the use of blended learning.

\section{Scenario \#1}

The problem. You have been assigned to teach a face-to-face course in a non-traditional program. There is plenty of class time, but the class time is too compressed in terms of the calendar, or class meetings are too long (e.g. eight hour days) for effective teaching and learning.

The solution. Use blended learning techniques to "stretch out' the calendar length of the course and/or reduce the length of class meetings.

Discussion: DePaul's Graduate School of Business has had several overseas M.B.A. programs within which this solution has sometimes been employed. One example is from a program in the Czech Republic. The face-to-face structure was three consecutive weekends of Friday night (four hours) and all-day Saturday (eight hours) class meetings. The 36 hours of total class time actually exceeded what is customary for a DePaul course. However, one professor teaching in the program was concerned that 12 hours of class time in a 24 hour time period would leave both the students and the professor mentally (and physically) exhausted well before the end of class on Saturday. His solution was to shorten both the Friday night and Saturday class meetings to the point where they were manageable, and to cover a portion of the course content through online videos and assignments, which the students would work on at their own pace between the weekends.

Another example comes from a DePaul M.B.A. program in Taiwan. Here, the face-to-face schedule was very calendar compressed, i.e., two consecutive weeks of class meetings on Thursday night (three hours), Saturday afternoon (five hours), and all-day Sunday (eight hours). So, the course was designed to have all of the course content covered over only 11 calendar days. The same professor from the previous example (Czech Republic) decided to "stretch out" the calendar length of the course by requiring that the students view online videos and do online assignments prior to the official start of the course and before the professor even arrived in Taiwan. A quiz covering the online material, given on the first Thursday night meeting, and about which the students were informed in advance, helped to increase the likelihood that the strategy would be effective.

\section{Scenario \#2}

The problem. You are teaching a face-to-face course, and a weather-related event has reduced the amount of class time to an unacceptable degree. 
The solution. Employ blended learning strategies to fix the problem on an after- the-fact basis.

Discussion: In 2007, a professor was teaching in DePaul's Taiwan M.B.A. program when a typhoon hit the island and caused the cancellation of the second of two all-day Sunday class meetings. In essence, the last eight hours of the course were ripped away by the typhoon. The professor could not re-schedule additional live meetings because he was scheduled to fly back to the U.S. the next day. His solution was to return to the U.S., record the last eight hours of class time, and make those recordings available to the students online. Student questions and/or comments were handled through e-mail. What began as a course disaster turned out to be a manageable problem through the use of blended learning techniques.

Less dramatic weather-related episodes can also be managed through blended learning strategies. For example, canceled classes due to snow are commonplace in many locations. A professor can simply record and place online whatever lecture and/or assignments were canceled due to the snow.

\section{Scenario \#3}

The problem. You are involved in a very specialized face-to-face teaching program. Perhaps multiple instructors each teach portions of the program. The program is specialized in that its schedule cuts across traditional semester or quarter schedules of colleges, and the pool of instructors willing and able to teach in the program is rather limited. The scheduling of instructors into the program's face-to-face sessions is difficult, due to conflicts with other, traditional, courses being taught by instructors, as well as by work-related conflicts for part-time instructors with full-time non-academic careers.

The solution. On an "as needed" basis, make use of blended learning techniques to "patch over" the scheduling conflicts.

Discussion. DePaul's C.P.A. review program is a very intensive, months-long program meeting three nights per week. The team of instructors has typically included 10-12 team members, including full-time faculty and part-time faculty with non-academic careers. Recruiting and scheduling faculty into the face-to-face sessions has always been difficult, as the pool of potential instructors willing to teach in such an intense program is limited, and part-time faculty with full-time careers often are traveling for work or temporarily assigned elsewhere.

As of the time of this writing, DePaul is in the process of developing a fully online C.P.A. review course. The auditing portion of the course is essentially complete, with the remaining portions in varying stages of completion.

As luck would have it, one of the instructors who teaches a number of the auditing sessions recently accepted an out-of-town consulting engagement, making it impossible for him to teach the upcoming live sessions.

A decision was made to make use of, within the face-to-face review course, the instructor's videotaped auditing sessions from the online review course. This effectively turns the auditing portion of the face-to-face review course into a blended course. Students will be fully informed of this change prior to enrollment.

Going forward, once the online review course is fully developed, future scheduling problems within the face-to-face review course can be solved in similar fashion.

\section{Scenario \#4}

The problem. You teach a course that is content heavy. Every semester/quarter, you struggle to cover all of the material by the end of the course.

The solution. Place the first-class session "administrivia" online. 
Discussion. In many, if not most, courses, a significant portion of the first face-to-face meeting is devoted to routine administrative tasks such as discussing the goals for the course, going over the syllabus, discussing how grades will be determined, etc. This "administrivia" is ideally suited to be handled through an online session, which students can do before the formal start of the course. The first face-to-face meeting could begin by addressing any student questions and/or comments concerning the administrative issues covered online, and then could quickly move to the actual course content, thereby freeing perhaps as much as an hour of face-to-face class time for more productive uses.

\section{CONCLUSION}

Blended courses and blended learning have a well-established track record of delivering educational benefits (Arbaugh, et al 2009). Institutions view blended courses as a discrete option that will be useful in the longrun. Consumers prefer and are open to blended delivery, even when they have not experienced it, which suggests that blended courses have room to grow in use.

Beyond the traditional or initial uses of blended courses, blended learning strategies can be employed in innovative ways to solve real-world academic problems. Examples include using blended learning to "stretch-out" calendar compressed courses, shorten excessively long face-to-face meetings, solve weather related problems, ease faculty scheduling, and eliminate the need to use valuable face-to-face time on mundane administrative issues. Both administrators and faculty can benefit from exposure to these problems and adapt solutions in their institution's environment (Owen \& Allardice, 2007).

\section{AUTHOR INFORMATION}

Mark A. McCarthy, JD, MAS, CPA, CMA is an Assistant Professor in the School of Accountancy and Management Information Systems of DePaul University, Chicago, Illinois. His primary teaching interests are managerial accounting and taxation. He also serves as the Director of DePaul's C.P.A. Review program.

Elizabeth A. Murphy, PhD, MBA, CPA is an Associate Professor in the School of Accountancy and Management Information Systems of DePaul University, Chicago, Illinois. Her primary teaching interests are financial, governmental, and not-for-profit accounting. She has earned multiple teaching awards from DePaul University, the Illinois CPA Society (2005 Outstanding Educator Award), and other organizations.

\section{REFERENCES}

1. Allen, I. Elaine, Jeff Seaman, and Richard Garrett. Blending In: The Extent and Promise of Blended Education in the United States. Sloan-Consortium ${ }^{\mathrm{TM}}$, Needham, MA, 2007. http://www.sloanc.org/publications/freedownloads.asp

2. Arbaugh, J. B., Michael R Godfrey, Marianne Johnson, Birgit Leisen Pollack, Bruce Niendorf, and William Wresch, Research in Online and Blended Learning in the Business Disciplines: Key Findings and Possible Future Directions, Internet and Higher Education, Vol.12, pp. 71-87, 2009.

3. Bonk, C. J. and C. R. Graham, Handbook of Blended Learning: Global Perspectives, Local Designs, Pfeiffer Publishing, San Francisco, CA, 2006.

4. Carnevale, Dan., U. of Illinois at Springfield Wants to 'Mirror' All Classroom Programs Online. The Chronicle of Higher Education, Vol. 50, No. 32, p. A34. 2004.

5, Moore, Janet C., ALN Principles for Blended Environments: A Collaboration. Sloan C Online Research Workshop. Sloan Consortium, 2004. http://www.sloan-c.org/publications/freedownloads.asp

6. Moore, Janet C., A Synthesis of Sloan-C Effective Practices. Journal of Asynchronous Learning Networks, Vol. 12, pp. 99-118, 2008.

7. Owen, Hazel and Rory Allardice, Managing the Implementation of Blended e-Learning Initiatives with the Unconverted in a Climate of Institutionally Driven Change. The International Journal of Learning, Vol. 14, pp. 179-191, 2007.

8. Parry, Marc, They Thought Globally, but Now Colleges Push Online Programs Locally. The Chronicle of Higher Education, Vol. 55, p. A9, 2009.

9. Young, Jeffrey R., 'Hybrid' Teaching Seeks to End the Divide Between Traditional and Online Instruction. The Chronicle of Higher Education, Vol. 48, p. A33. 2002. 